\title{
Música Doméstica e Tecnologia
}

\author{
Ricardo Tacuchian
}

Este trabalho é uma reflexão sobre as relações existentes entre o declínio da música doméstica no início do século $X X$, pela ação de uma nova tecnologia eletro-eletrônica, ea sua recuperação, também pela ação da tecnologia, já neste final de século. Usamos a designação "música doméstica" para aquela feita em casa, nas horas de lazer, por músicos amadores; e delimitamos a expressão a uma prática mais urbana, excluindo arica manifestação folclórica, queéuma tradição predominantemente rural.

$\mathrm{Na}$ Idade Média, já era comum a família se reunir em torno de uma mesa para cantar um moteto, cujas partes eram dispostas no papel, de modo que cada cantor pudesseler o texto sem deixaro seu assento. Ainda os Mestres-Cantores eram artesãos, que preenchiam suas horas de lazer com uma prática musical.

$\mathrm{Na}$ Renascença, a música doméstica era muito difundida, apesar de não ter a mesma repercussão daquela feita por profissionais, nas casas da nobreza ou na Igreja. Era uma música intimista, cantada por vozes brancas, algumas delas substituídas por um instrumento musical.

Na passagem da Renascença para o Barroco, a música vocal passa a ser paulatinamente substituída pela música instrumental no repertório da música doméstica. Uma emergente classe mercantil vai, aos poucos, substituindo a classe aristocrática que, simbolicamente, é degolada na Revolução Francesa. Com o enriquecimento, e dispondo de mais tempo para o lazer, a classe média, que também gostava de imitar a nobreza, fazia música em casa, apesar de não poder contar com a participação de músicos profissionais. Este fato trouxeumgrande desenvolvimento para aindústria demanufatura deinstrumentos, principalmente o piano, e para a impressão de músicas de amadores. 
Em 1765, o impressor Immanuel Breitkopf encontrou um novo método deimpressão musical, que muito barateou a difusão de partituras para uso doméstico, tanto para piano ou canto e piano, como para pequenos conjuntos camerísticos. No século XVIII, foi muito rara a impressão de música para profissionais, especialmente para orquestra, porque não era comercialmente viável. A maior parte das publicações editadas em Londres, Paris, Leipzig e Viena, na passagem do século XVIII para o XIX, era de música para amadores, de larga procura no mercado'. Nessa ocasião, era curioso, por exemplo, o hábito de se escrever música para piano com acompanhamento de violino ou flauta. O próprio Beethoven chegou a compor variações para piano com flauta ou violino opcionais, as op. 105 e 107. Antes, em 1781, Mozart já chamara Viena de "a terra do piano", referindo-seà popularidade deste instrumento entre os amadores.

No século XVIII, foi publicada uma quantidade infindável de canções, com simples estrutura estrófica, geralmente impressas em apenas duas pautas, com a letra escrita entre as duas. A peça poderia ser tocada e cantada pelo mesmo intérprete, ou apenas ser tocada ao piano.

Em 1798, surgiu em Leipzig o Allgemeine musikalische Zeitung, periódico destinado a atender à nova demanda de amadores e incentivar a venda, para eles, de partiturase deinstrumentos musicais.É sintomático o fato de ter sido lançado por uma casa editora, a Breitkopf un Härtel, provavelmente com o objetivo de aumentar as suas vendas. Entre 1798 e 1848, surgiram outras duzentas e sessenta publicações destegênero nas principais cidades da Europa. Estes jornais ou revistas traziam artigos sobremúsica em geral, críticas de concertos edeobras recém-publicadas, reportagens e entrevistas, suplementos musicais e anúncios de casas editoras.

Por outro lado, há referências de que, na cidade de Viena, durante o carnaval de 1821, houve cerca de mil e seiscentos bailes em casas particulares ${ }^{2}$. São bem conhecidas as Schubertíadas, festas que o renomado compositor vienense fazia no campo para seus amigos. Schubert compôs muita música de excelente qualidade destinada a um público amador, como os ländlers, valsas, marchas, rondós, variações e canções. Os seus quartetos, escritos entre 1812 e 1815, foram direcionados a amadores. Grande parte da produção camerística com 
piano, do século XIX pretendia alcançar os músicos amadores. Geralmente, o piano exercia um papel preponderante, enquanto as cordas funcionavam subservientemente.

O enfoque, na obra dos grandes mestres do século XIX, tem deixado delado este importante aspecto da vida musical, que foi a música doméstica, agora resgatada pelos modernos historiadores como fato da maior relevância. Naturalmente, o Rio de Janeiro, como reflexo das tendências européias deentão, tambémapresenta umgrandeflorescimento da música doméstica durante o século XIX. Esta música ganha desenvoltura no tempo de D. Pedro I que, por motivos econômicos, foi obrigado a reduzir drasticamente a música praticada na corte. Ao lado disso, começa a ascender uma nova classe urbana, enriquecida no comércio, que freqüenta o teatro, mas também faz música em casa. Surgem, então, no Rio, vários professores estrangeiros, principalmente de piano, que se mantêm dando aulas particulares para as filhas da classe média emergente.

Já nosidos de 1823, foi publicado o primeiro compêndio de música no Brasil, a Arte da Música para uso da mocidade brasileira, por um seu patricio, na Tipografia de Silva Porto e Cia. Lembremos que, atéD. Joao VI, não havia imprensa no país. Em 1824, foi lançado outro compêndio didático, este de autoria da Bonifácio Asioli. O comércio de música, com a venda de partituras e instrumentos, como ocorreu na Europa, ganhou um grande incremento. A primeira notícia da chegada de uma pianolano Rio éde 1823․ Cita Ayres de Andrade que, "em 1829, J. Christian Müller, mestre consertador e afinador de piano promove a primeira publicação de música em série de que se há notícias no Brasil" 4 .

Em 1834, foi fabricado o primeiro piano no Rio. Este instrumento se tornou tão popular nas casas de classe média brasileiras, que levou Mário de Andrade a cunhar o termo "pianolatria". As músicas de sucesso, apresentadas nos teatros de revista, eram vendidas no dia seguinte, em reduções simplificadas para piano. Chiquinha Gonzaga foi um exemplo de compositor que se beneficiou desta prática.

A literatura brasileira é úbere de citações de saraus, encontros poético-musicais de caráter informal, realizados em casas particulares. Na segunda metade do século XIX, as classes mais pobres também cultivavam a música doméstica em festas residenciais, que eram chama- 
das de "pagodes". Lá se desenvolviam o maxixe e o choro, duas raízes básicas da música popular brasileira.

O ensino de música para a classe média inicia-se no Rio, com aulas específicas ministradas no Colégio Pedro II, em 1838. Em 1841, foi criado o primeiro estabelecimento privado de ensino musical: o Liceu Musical. Até 1865, surgiram o Conservatório de Música e Dança, o Liceu Musical e Copistaria, o Conservatório Vocal e Instrumental e muitos outros. Todos eram dirigidos para uma prática musical amadorística. Mesmo o Imperial Conservatório de Música (criado em 1848) atendia muito mais aos interesses de músicos amadores do que de profissionais, apesar de ter formado, por exemplo, um músico como Carlos Gomes.

Mas, por trás deste panorama da música doméstica, começava a surgir um fato novo, que sorrateiramente viria a banir toda esta atividade amadorística residencial: a tecnologia da gravação e da radiodifusão. Em 1877, Thomas Edison consegue aprisionar o som em cilindros, que são capazes de reproduzi-lo para qualquer ouvinte, numa máquina chamada "fonógrafo". Seguem-se o gramofone, de Emil Berliner, e a vitrola, de Eldridge Johnson, ambos registrando o som em discos. Em 1919, nos Estados Unidos, mais de dois milhões de fonógrafos já tinham sido fabricados e as vendas de discos chegavam perto de cem milhões de unidades por ano $\mathrm{s}^{5}$.

O ano seguinte é o do início da radiodifusão. O Dr. Frank Conrad instalou sobre sua garagem, em Pittsburgh, os equipamentos necessários para a transmissão de música gravada. Apesar de poucas pessoas possuírem aparelhos especialmente montados para receber estas ondas, aumentou de modo surpreendente a venda dos discos, que eram transmitidos por aquela estação experimental. O pragmatismo norteamericano logo percebeu que aquela tecnologia poderia ser fonte de lucros incomensuráveis. No mesmo ano, a Westinghouse começou a vender aparelhos receptores prontos e a própria firma inaugurou a estação de rádio KDKA, em 1920, para promover a venda de mais receptores de radio. Apenas dois anos maistarde, sessenta mil residências já tinham aparelhos de rádio e trinta estaçõesjá estavam no ar ${ }^{6}$.Em 1927, estes números pularam para sete milhões de residências com aparelhos e setecentas estações de rádio. Em 1931, foram feitas as primeiras 
transmissões radiofônicas "ao vivo" do Metropolitan Opera, pela rede NBC. Era o golpe mortal para a música doméstica. Antes, em 1927, já havia surgido o cinema sonoro com o filme The Jazz Singer.

Em 1947, era crescentea aceitação de gravações em fita magnética. Em 1948, surgiu o long-playing e, em 1966, a fita-cassete com gravações estereofônicas. Finalmente, a TV para cabo $M T V$ passou a transmitir vídeos de música vinte e quatro horas por dia e, em 1983, surgiu o compact-disc.

Assim como o Brasil refletiu as tendências ocorridas na Europa, no século XIX, o mesmo ocorreu no século XX, em relação aos Estados Unidos. O fonógrafo de Thomas Edison aqui chegou ao Brasil dois anos depois de inventado, isto é, em 1879, na cidade de Porto Alegre ${ }^{7}$. Mas o primeiro comerciante das máquinas falantes e dos cilindros de Thomas Edison começou sua trajetória de caixeiro viajante no Amazonas, percorrendo todo o Nordeste e chegando ao Rio em $1892^{\circ}$. Frederico Figner - este era o seunome - apresentava duas sessões da máquinafalante por dia, cobrando ingressos no valor de $1 \$ 000 .{ }^{9}$

O fonógrafo de cilindros foi logo comercializado em todo o litoral brasileiro e em Minas Gerais. Em 1897, Figner começa a gravar cilindros com música popular brasileira com os cantores Antônio da Costa Moreira, o Cadete, e Manuel Pedro dos Santos, o Baiano, cantando modinhas e lundus com acompanhamento de violão; e com Anacleto de Medeiros, com a recém-criada Banda do Corpo de Bombeiros do Rio de Janeiro ${ }^{10}$.

Em 1904, entra no mercado brasileiro o gramofone, com os discos de cera de Émile Berliner.

No dia 7 de setembro de 1922, o presidente Epitácio Pessoa faz o discurso de inauguração da Exposição Internacional do Rio de Janeiro, transmitido por uma estação montada pela pioneira Westinghouse e reproduzida através de um telefone-falante. A partir dai, os programas eram transmitidos através de alto-falantes e de cerca de oitenta receptadores cedidos a personalidades do Rio ou em praças públicas. É o início da era da radiodifusão no Brasil.

O desenvolvimento fulgurante de toda esta tecnologia de gravação e de radiodifusão, que culmina hoje com o compact-disc, o video-disc e o $C D-R O M$, provocaram um alto nível de profissionalização, tanto na 
música de concerto quanto na música popular (vide os mega-stars da música pop), mas quase acabaram com a música doméstica.

Atualmente, ocorre um fato da maior relevância para a sociologia da música. A mesma tecnologia que inibiu a música doméstica a está ressuscitando. Ao lado da tecnologia de radiodifusão e de gravação do som, nos anos 50, surgiu uma $3^{\mathrm{a}}$ linhagem de equipamentos eletroeletrônicos: os sintetizadores de som. Inicialmente gigantescos e caros, ganham impulso nos anos 60 com o princípio estabelecido por Robert Moog, de sintetizador controlado por diferença de voltagem, tais como Buchla, o Syn-ket e o próprio Moog.

Mas foi nos anos 70 que estes instrumentos ganharam um aperfeiçoamento que iria mudar a relação entre música doméstica e tecnologia. Foi o advento do uso da tecnologia digital na construção do sintetizador, com o lançamento do Dartmouth Digital Synthesizer. O sintetizador deixa de séruminstrumento analógico eentra na era da tecnologia digital, com todas as vantagens que isso representa: maior facilidade de operação, maior precisão na definição dos parâmetros, mais variedade de recursos, possibilidade de preservar a música numa memória para depois resgatá-la e reeditá-la, e o menor preço. O Synclovier (1976) e o Synclavier II (1980) já vêm acoplados a um computador que controla todos os parâmetros da síntese sonora e todas as operações algorítmicas.

Outra grande revolução ocorreria no mundo da tecnologia do som: a definição do protocolo MIDI (1983), que permitiria a troca de informações entre diferentes teclados (agora não mais chamados de sintetizadores) e entre eles eum computador. A partir daí, cada vez mais foram se sofisticando os aparelhos ou surgindo novos (como éo caso dos samplers e dos sample-players), para uso profissional ou se simplificando, parauso de amadores. Atualmente, continuam surgindo no comércio teclados destinados a um público amador que, num mini-estúdio doméstico, monta seus arranjos e suas orquestrações com grande facilidade. Vários profissionais de outras áreas procuram esta aparelhagem para fazer música nas horas de lazer. Mesmo no campo da música eletroacústica, cada vez mais se faz presente a figura do criador que não tem uma formação musical convencional habitual. Como o preço desta tecnologia vem despencando, a tendência éa popularização progressiva desta prática. 
Além da tecnologia da computer music, o surgimento e aperfeiçoamento da guitarra elétrica permitiu a um grupo crescente de jovens, no mundo inteiro, formarem suas bandas, ensaiando em apartamentos, muitas vezes para desespero dos vizinhos. A guitarra elétrica de corpo sólido surgiu nos anos 40, mas adquiriu popularidade internacional com o advento do rock'n'roll a partir dos anos 60.

No Rio de Janeiro tem surgido um grande número de pequenas escolas particulares de música, que romperam com o formato educativo tradicional até então usado e iniciam as crianças em teclados eletrônicos. Os adultos também recorrem a estas escolas.

Estamos assistindo, no momento, a um renascer da música doméstica, graças ao grande desenvolvimento da tecnologia, a mesma que a tinha conduzido quase à extinção. E hoje, com uma vantagem adicional em relação ao século XIX: o amador faz música em seu quarto, nas horas de lazer, e depois assiste a uma ópera ou a um concerto em video laser em sua sala. São apenas alguns passos.

\section{Referências Bibliográficas}

ANDRADE, Ayres de. Francisco Manuel da Silva e seu Tempo. Rio de Janeiro, Tempo Brasileiro, 1967. 2 vol.

PLANTINGA, Leon. Romantic Music. New York / London, W.W. Norton, 1984.

SABLOSKY, Irving L. A Música Norte-Americana. Rio de Janeiro, Zahar, 1994.

TINHORÃO, José Ramos. Música Popular: do Gramofone ao Rádio e TV. São Paulo, Ática, 1981.

\section{Notas}

1. Leon Plantinga, Romantic Music, p. 10.

2. Ibidem, p. 82.

3. Ayres de Andrade, Francisco Manuel da Silva e seu tempo, I, p. 134.

4. Ibidem, p. 135.

5. Irving L. Sablosky, A Música Norte-Americana, p. 111.

6. Ibidem, p. 113.

7. Atos Damasceno, Palco, salão e picadeiro, Porto Alegre, Globo, 1956, p. 11, 
181. Apud J. R. Tinhorão, Música Popular: do gramofone ao rádio e TV, p. 15. 8. J. R. Tinhorão, Música Popular: do gramofone ao rádio e TV, p. 18.

9. Figner foi, mais tarde, o fundador da Casa Edison, a primeira gravadora comercial do Brasil.

10. J. R. Tinharão, op. cit., p. 20-21.

Ricardo Tacuchian é Compositor, Professor Titular da Escola de Música da Universidade Federal do Rio de Janeiro e Presidente da Academia Brasileira de Música. 